\title{
Statistical Analysis of Sulfate Attack Resistance of Reactive Powder Concrete
}

\author{
Umut Bektimirova $^{1}$, Eldar Sharafutdinov ${ }^{2}$, Chang S. Shon ${ }^{3}$, Dichuan Zhang ${ }^{4}$, and \\ Jong R. Kim ${ }^{5}$
}

${ }^{1}$ Department of Civil and Environmental Engineering, Nazarbayev University, 53 Kabanbay batyr avenue, Nur-Sultan, Kazakhstan, 010000, ubakhbergenova@nu.edu.kz

${ }^{2}$ Department of Civil and Environmental Engineering, Nazarbayev University, 53 Kabanbay batyr avenue, Nur-Sultan, Kazakhstan, 010000, esharafutdinov@nu.edu.kz

${ }^{3}$ Department of Civil and Environmental Engineering, Nazarbayev University, 53 Kabanbay batyr avenue, Nur-Sultan, Kazakhstan, 010000, chang.shon@nu.edu.kz

${ }^{4}$ Department of Civil and Environmental Engineering, Nazarbayev University, 53 Kabanbay batyr avenue, Nur-Sultan, Kazakhstan, 010000, dichuan.zhang@nu.edu.kz

${ }^{5}$ Department of Civil and Environmental Engineering, Nazarbayev University, 53 Kabanbay batyr avenue, Nur-Sultan, Kazakhstan, 010000, jong.kim@nu.edu.kz

\begin{abstract}
This paper is the study of sulfate attack resistance of reactive powder concrete (RPC). RPC that is also known as ultra-high performance concrete is a special type of concrete material obtained when fine powders like silica fume (SF) are added into the concrete mortar along with very low waterto-binder ratio $(w / b)$. SF is a pozzolanic material obtained as a by-product of silicon metal or ferrosilicon alloys production. In this study, total 6 different $R P C$ mixtures with various $w / b(0.18,0.22$ and 0.26) and various SF content were studied. SF was added into the concrete mixtures in the amount of $15 \%, 20 \%$ and $25 \%$ of cement by weight. The other testing parameter includes 3 different concentrations of sodium sulfate ( $\left.\mathrm{Na}_{2} \mathrm{SO}_{4}\right)$ solutions ( $0.35 \mathrm{M}, 0.7 \mathrm{M}$ and $1.4 \mathrm{M}$ concentrations). Broad laboratory investigations of behavior of the RPC mixtures were conducted in terms of compressive strength and mass gain of cubes $\left(50 \times 50 \times 50 \mathrm{~mm}^{3}\right)$ and expansion and mass change as in accordance with ASTM C1012. Test results had been analyzed and assessed by Taguchi method. The significance level of experimental parameters was determined by using Analysis of variance (ANOVA) method. According to statistical and analytical results it was observed that RPC has high sulfate attack resistance. Moreover, addition of optimal amount of SF into the RPC mixtures as well as decreasing $w / b$ can significantly improve $\mathrm{Na}_{2} \mathrm{SO}_{4}$ resistance of $\mathrm{RPC}$.
\end{abstract}

Keywords: Reactive Powder Concrete, Taguchi Method, Silica Fume, Sulfate Attack Resistance.

\section{Introduction}

Sustainable development concept has recently become one of the most important topics in the construction industry. Moreover, development of alternative sources of energy in the face of energy crisis due to limited natural resources is foremost issue of the industry. Compressed air energy storage system incorporated into pile foundation system of the apartment building is proposed as a viable alternative to accumulating excess energy from solar panels installed on the building during the off-peak hours to be able to use it during the increased demand periods (Tulebekova et al., 2017, Zhang et al., 2018). Hence, complex structural and internal loading conditions require the piles to be made of superior performance material such as ultra-high performance concrete (Tulebekova et al., 2019). Reactive Powder Concrete (RPC) is a type of 
ultra-high performance concrete that is obtained by removing coarse aggregates from and addition of pozzolanic materials like silica fume (SF) to the concrete along with very low waterto-binder ratio (w/b) (Sun et al., 2015). RPC has a densified microstructure that is attributed to the removal of coarse aggregates and the pozzolanic reaction that lead to the formation of strong bonds in interfacial transition zone due to the increased formation of strong calcium silicate hydrate lattices (Beglarigale and Yazıc1, 2015). It was investigated that the optimization of SF content and $\mathrm{w} / \mathrm{b}$ results in the RPC with very high compressive and tensile strength (Ahmad et al., 2015; Bektimirova et al., 2018). Moreover, compressive strength of RPC could be increased further by optimization of packing degree of small aggregate (Ji et al., 2011, Bektimirova et al., 2020). Nevertheless, RPC is a relatively new type of concrete material, and its durability properties is still an ongoing topic of research.

External sulfate attack (ESA) is a concrete durability issue arising from the migration of sulfate ions from surrounding soils into the concrete structure, resulting in the series of chemical reactions and physical processes that cause irrecoverable damage to material (Marchand et al., 2003). Even though the exact mechanism of sulfate attack is still questionable, it is agreed that the physical damage in the material occurs through the formation of expansive products such as gypsum and ettringite (Tixier and Mobasher, 2003) that leads to dimensional expansion and mass gain of the specimen. Expansive products form in the cracks in the microstructure of concrete and exert pressures that could be sustained by the pore spaces in the material (Ikumi et al., 2019). However, the extensive or prolonged formation of expansive products might lead to the irreclaimable damage to concrete microstructure causing material degradation, loss of cohesiveness and strength (Gu et al.,2019). Although Haufe and Vollpracht (2019) reported
that RPC has moderate to high resistance to ESA due to its improved microstructure and
reduced porosity, little data are available on the ESA resistance of RPC.
In this study, the ESA resistance of different RPC mixtures was investigated. SF content
w/b, and concentration of sodium sulfate $\left(\mathrm{Na}_{2} \mathrm{SO}_{4}\right)$ solution were selected as prinary factors to influence on the compressive strength and expansion of the RPC mixtures exposed to the ESA

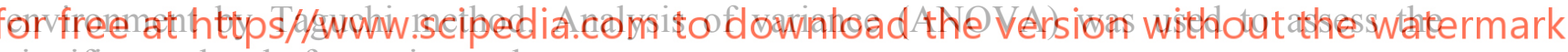
significance level of experimental parameters.

\section{Experimental Program}

\subsection{Materials}

Ordinary Portland cement (ASTM type I) and SF with specific gravities 3.15 and 2.22 correspondingly were used as binder materials in this study. The chemical composition of cement and SF is provided in Table 1. Locally available quartz sand with specific gravity 2.4, absorption capacity of $6.2 \%$ was used as a fine aggregate for the RPC mixtures.

Liquid superplasticizer (SP) Master Glenium ACE 430 with specific gravity 1.02, and ordinary tap water were used in RPC mixing. 
Table 1. Chemical composition of binders.

\begin{tabular}{ccc}
\hline Components & Cement & SF \\
\hline $\left.\mathrm{CaO}_{0 \%}\right]$ & 65.91 & 0.22 \\
$\mathrm{SiO}_{2}[\%]$ & 21.55 & 97.54 \\
$\mathrm{Al}_{2} \mathrm{O}_{3}[\%]$ & 5.55 & 0.2 \\
$\mathrm{Fe}_{2} \mathrm{O}_{3}[\%]$ & 4.7 & 0.06 \\
$\mathrm{SO}_{3}[\%]$ & 1.9 & - \\
$\mathrm{MgO}[\%]$ & 1.46 & - \\
$\mathrm{K}_{2} \mathrm{O}[\%]$ & 0.35 & - \\
Loss on Ignition [\%] & 0.49 & 2.08 \\
\hline
\end{tabular}

\subsection{Mixture Proportion and Levels of Evaluation Variables}

The experiments were designed to analyze the influence of various w/b, SF content, and sulfate concentration on the compressive strength and expansion of RPC. Mixture proportioning of RPC mixtures was completed using the absolute volume method. The details of mixture proportion are provided in Table 2.

Table 2. Mixture proportion of RPC $\left(\mathrm{kg} / \mathrm{m}^{3}\right)$.

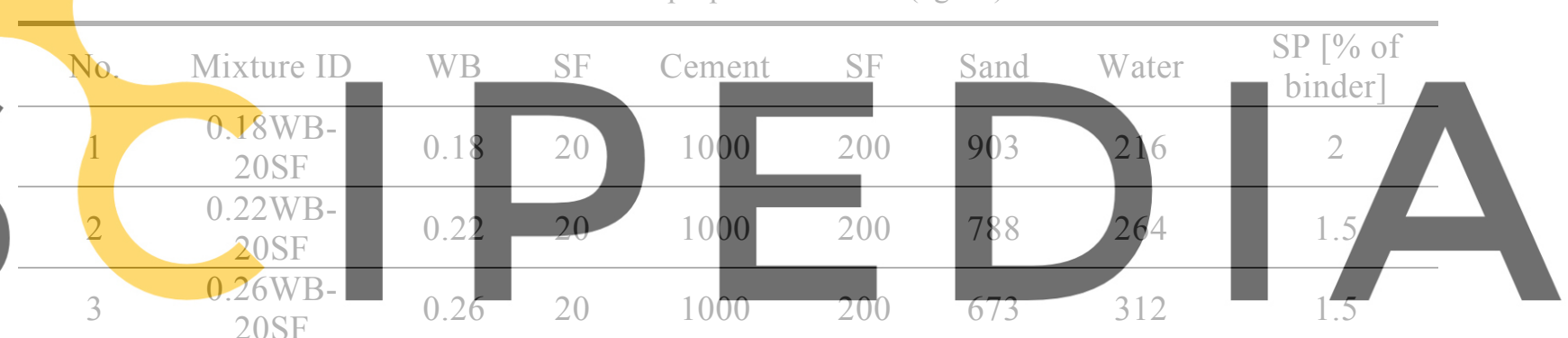

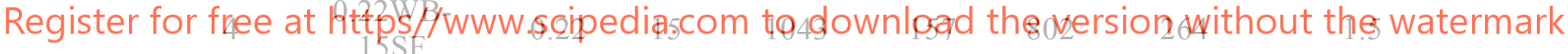

\begin{tabular}{lcllllllll}
\hline 5 & $0.22 \mathrm{WB}-$ & 0.22 & 25 & 960 & 240 & 776 & 264 & 1.5 \\
\hline
\end{tabular}

The Taguchi statistical analysis method was used to determine the optimal mixture that will have the maximum compressive strength and the highest ESA resistance which is determined by the lowest expansion and mass gain during the exposure. Taguchi analysis was performed for 3 factors at a time with 3 levels each. Thus, 2 sets of analyses were performed: first one for $\mathrm{w} / \mathrm{b}$, second one for SF content, while sulfate concentration and exposure time were factors of analysis for both sets. Factors and levels of Taguchi analysis are shown in Table 3.

Table 3. Levels of the variables in the experimental program.

\begin{tabular}{cccc}
\hline Factors & Level 1 & Level 2 & Level 3 \\
\hline $\mathrm{w} / \mathrm{b}$ & 0.18 & 0.22 & 0.26 \\
$\mathrm{SF}$ content & 15 & 20 & 25 \\
$\mathrm{Na}_{2} \mathrm{SO}_{4}$ concentration & 0.35 & 0.7 & 1.4 \\
$\mathrm{Time}_{\mathrm{rim}}$ exposure & 1 week & 4 weeks & 13 weeks \\
\hline
\end{tabular}




\subsection{Casting, Curing and Maintaining the Samples}

Mixing RPC was completed in pan type mixer with total mixing time of $9 \pm 1 \mathrm{~min}$. Immediately after mixing was complete, RPC was placed into the molds: $50 \times 50 \times 50 \mathrm{~mm}$ cube mold as required in ASTM C109 for compressive strength test; and, $25 \times 25 \times 250 \mathrm{~mm}$ prism molds as required by ASTM C1012 for length and mass change test. RPC specimens were cured for 24 hours in molds covered by plastic sheets to avoid water evaporation, after which they were placed into the $\mathrm{Na}_{2} \mathrm{SO}_{4}$ solution where they were stored until the test date.

\subsection{Test Methods}

The length and mass change tests of RPC were performed in accordance with ASTM C 1012 and ASTM C490 on the same samples. Accuracy of digital length comparator and digital scales used for measurements of length and mass change are $\pm 0.0001 \mathrm{~mm}$ and $\pm 0.001 \mathrm{~g}$ correspondingly. The compressive strength test of RPC was conducted in accordance with ASTM C109.

A number of samples are varied from mixture to mixture: 4-8 samples. To achieve better statistical reliability, outliers had been removed from calculated data as in accordance with ASTME178. The test set up is provided in Figures 1 (a) and 1 (b).
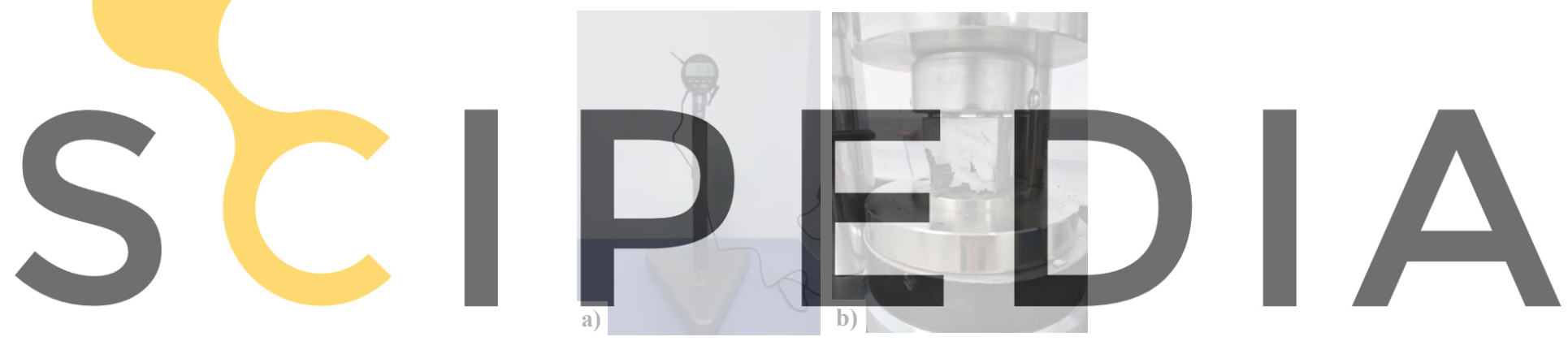

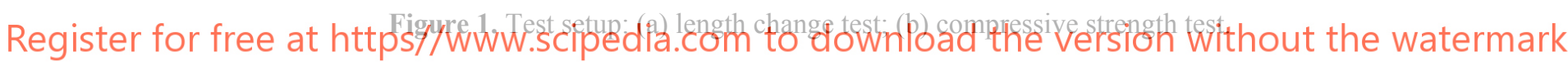

\section{Results and Discussion}

\subsection{Statistical Analysis}

General Linear Model of analysis of variance (ANOVA) was used to observe statistically important parameters of experiments. Furthermore, to assess the contribution percentage of each parameter to the compressive strength, length and mass change, P-value was used: smaller $\mathrm{P}$-value indicates more affective parameter in the concrete performance characteristics (Lin et al., 2000). The results of ANOVA for both sets of w/b-concentration-time and SF contentconcentration-time are shown in Table 5. 
Table 5. Results of ANOVA for w/b-concentration-time set and SF content-concentration-time set.

\begin{tabular}{cllll|llllrrr}
\hline Source & \multicolumn{1}{c}{ SS } & MS & F & P-Value & Source & SS & MS & F & $\begin{array}{c}\text { P- } \\
\text { Value }\end{array}$ \\
\hline \multicolumn{8}{c}{ ANOVA for Compressive Strength of RPC } \\
\hline w/b & 48 & 24 & 0.31 & 0.735 & SF & 472.6 & 236.29 & 2.16 & 0.142 \\
conc & 329.4 & 164.7 & 2.15 & 0.143 & conc & 143.4 & 71.72 & 0.65 & 0.53 \\
time & 4731.02 & 2365.51 & 30.86 & 0 & time & 4090.2 & 2045.12 & 18.67 & 0 \\
\hline \multicolumn{8}{c}{ ANOVA for Length Change of RPC } \\
\hline w/b & 0.002954 & 0.001477 & 41.65 & 0 & SF & 0.001211 & 0.000605 & 19.76 & 0 \\
conc & 0.000478 & 0.000239 & 6.74 & 0.006 & conc & 0.000404 & 0.000202 & 6.59 & 0.006 \\
time & 0.000484 & 0.000242 & 6.82 & 0.006 & time & 0.000353 & 0.000177 & 5.77 & 0.011 \\
\hline \multicolumn{8}{c}{ ANOVA for Mass Change of RPC } \\
\hline w/b & 6.1525 & 3.07624 & 41.31 & 0 & SF & 0.3926 & 0.1963 & 7.22 & 0.004 \\
conc & 1.1562 & 0.57808 & 7.76 & 0.003 & conc & 2.604 & 1.302 & 47.89 & 0 \\
time & 0.8825 & 0.44127 & 5.93 & 0.01 & time & 1.0554 & 0.52768 & 19.41 & 0 \\
\hline
\end{tabular}

According to Table 5, time is the most important parameter for compressive strength in both sets of experiments while length change is controlled by w/b and SF factors in $\mathrm{w} / \mathrm{b}$ concentration-time and SF content-concentration-time sets respectively. Mass change is also

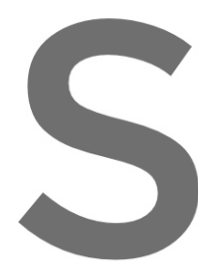
influenced mostly concentration-time set in suggest that time of exposur resistance of RPC.

3.2 Taguchi Anallysis
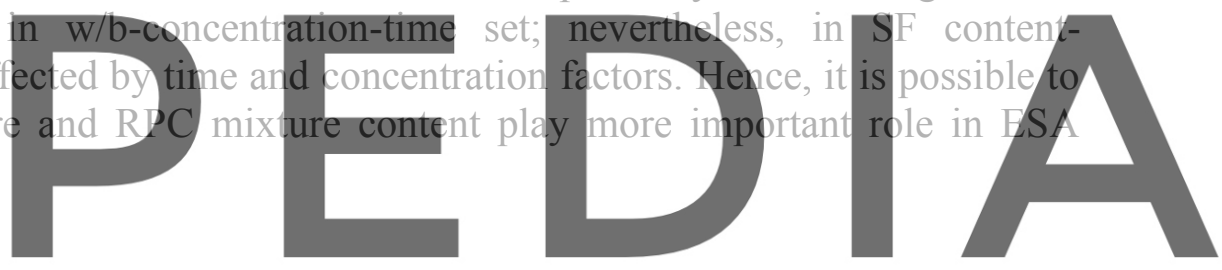

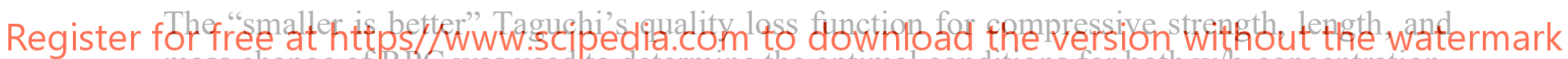
mass change of RPC was used to determine the optimal conditions for both w/b-concentrationtime and SF content-concentration-time sets. The loss function is transferred further into utility function called Signal-to-Noise ratio $(\mathrm{S} / \mathrm{N})$ developed by Taguchi. S/N allows to identify performance characteristic deviating from desired value (Rahimi et al., 2016). Noise factor is any factor that causes deviation from targeted value for measurable product or process characteristics. Minitab statistical software was used for the statistical analysis of the results which are discussed in following sections.

\subsubsection{Compressive strength}

The main goal of every experiment is to determine the highest possible $\mathrm{S} / \mathrm{N}$ value that will indicate that random effects of the noise factors are negligible compared to that of the signal. Fig. 2 shows the $\mathrm{S} / \mathrm{N}$ ratio of compressive strength for $\mathrm{w} / \mathrm{b}$-concentration-time and SFconcentration-time sets.

As presented in Fig. 2, the minimum variation in compressive strength was obtained for the RPC containing $\mathrm{w} / \mathrm{b}=0.26$ and $\mathrm{SF}=25 \%$. Fig. 2 also shows that optimal values of concentration and curing time are $0.35 \mathrm{M}$ and 1 -week in both w/b-concentration-time and SF contentconcentration-time sets. In fact, compressive strength of RPC generally tends to decrease with 
increasing the concentration of $\mathrm{Na}_{2} \mathrm{SO}_{4}$ solution: The higher concentration of $\mathrm{Na}_{2} \mathrm{SO}_{4}$ solution, the more deterioration of in RPC performance. It is possible to observe from Fig. 2 that $1.4 \mathrm{M}$ $\mathrm{Na}_{2} \mathrm{SO}_{4}$ solution not only has lower $\mathrm{S} / \mathrm{N}$ ratio, but also has more damaging effect on compressive strength than $0.7 \mathrm{M}$ solution. This result may be attributed to stoichiometry of chemical reaction occurring during the sulfate attack exposure of concrete: As the concentration of $\mathrm{Na}_{2} \mathrm{SO}_{4}$ solution increases, more sulfate ions penetrate in to the specimen, consequently leading to more deteriorative cracks inside specimen and the reduction of the strength.
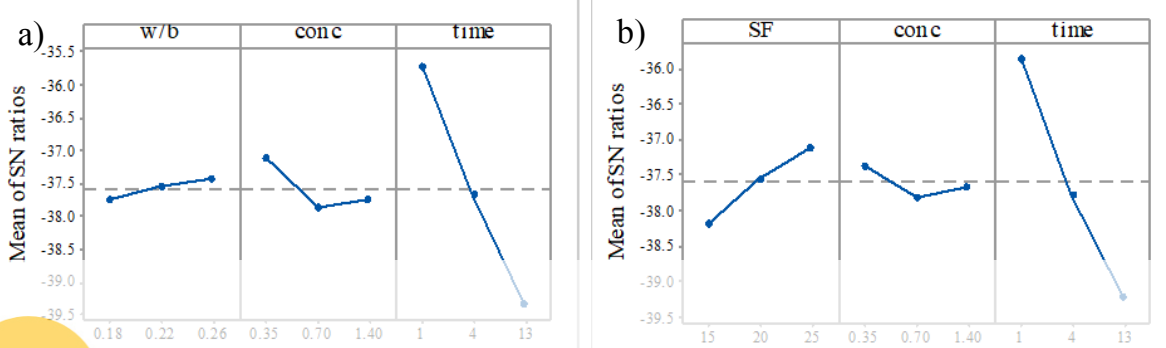

Figure 2. Main effects plots for SN ratios (Compressive strength): (a) w/b-concentration-time set; (b) SF content-concentration-time set.

\subsubsection{Length and Mass change}
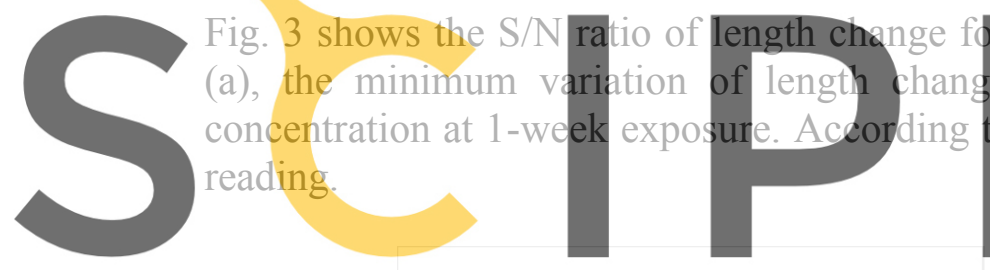

a)
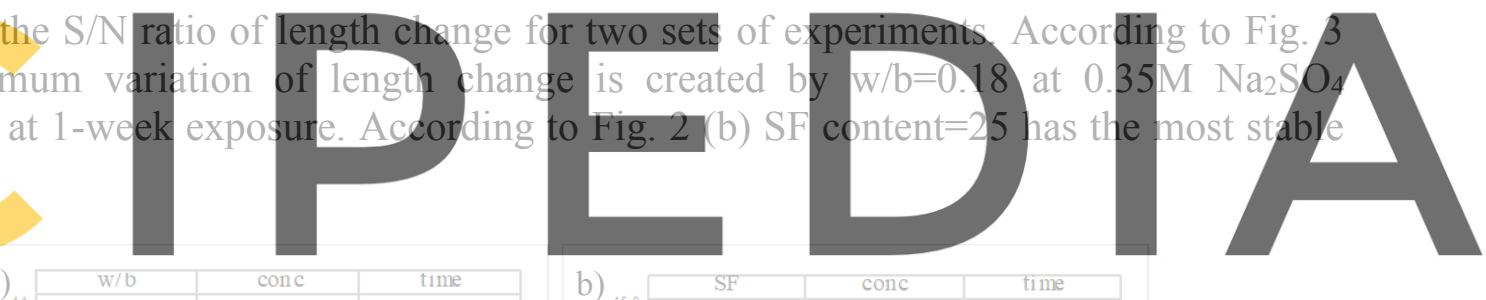

Register for free at lattps//www.scipedia.com to do

b)

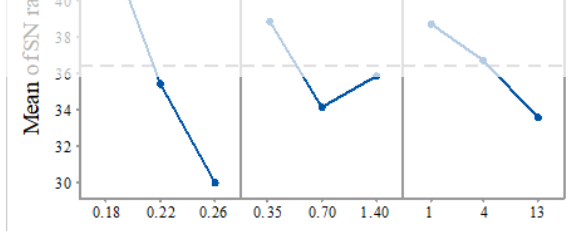

Signal-to-noise: Smalle is better

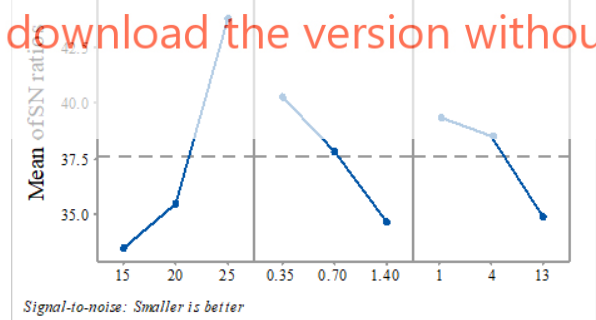

Figure 3. Main effects plots for SN ratios (Length change): (a) w/b-concentration-time set; (b) SF contentconcentration-time set.

Fig. 4 shows the $\mathrm{S} / \mathrm{N}$ ratio of mass change for two sets of experiments. Accordingly $\mathrm{S} / \mathrm{N}$ ratios of mass change show the same trends as for length change for both sets of experiments. The reason is possibly that the same samples were used for both measurements. Furthermore, expansion of RPC exposed to sulfate attack result in both mass gain and elongation of the sample. Thus, formation and accommodation of expansive products in the RPC internal structure is indicated by the mass gain of the samples. Moreover, the process of accommodation of expansive products (ettringite formation) leads to internal cracking resulting in the expansion 
of concrete. Hence, it appears to be logical that both length and mass change measurements show similar statistical behavior as it is observed by Taguchi analysis in this study.
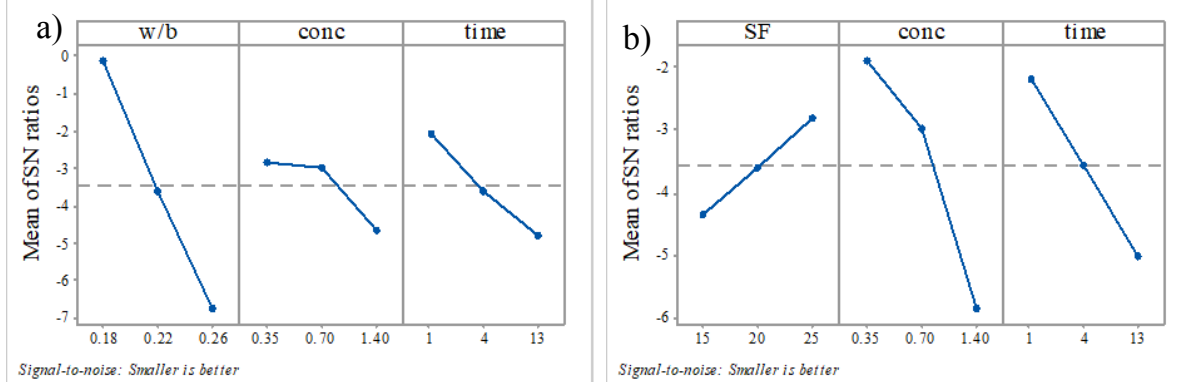

Figure 4. Main effects plots for SN ratios (Mass change): (a) w/b-concentration-time set; (b) SF contentconcentration-time set.

\section{Conclusion}

\section{Sulfate attack is an important durability problem of concrete structures exposed to groundwaters} containing sulfate ions as in case of pile foundations. RPC is a relatively new type of material that has superior durability and mechanical characteristics. This study statistically analyzed sulfate attack resistance of RPC in two sets of influence factors. Accordingly, the following conclusions can be made:
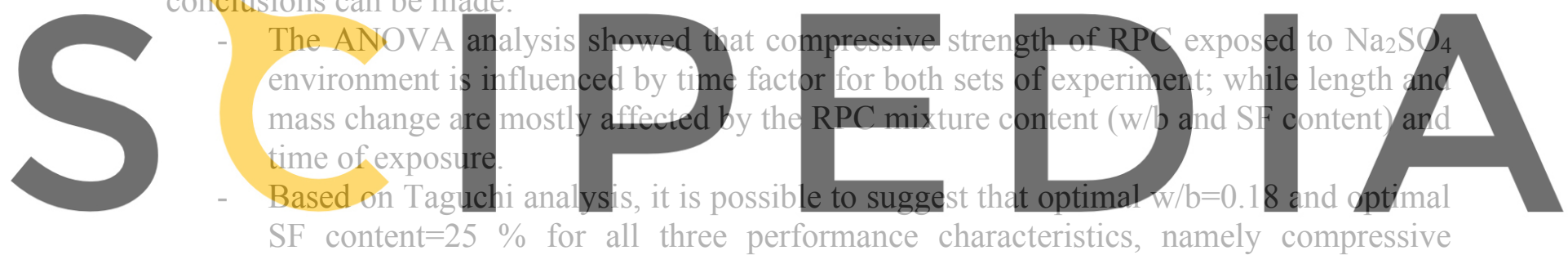

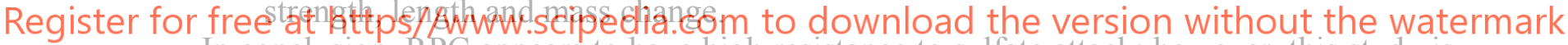
In conclusion, RPC appears to have high resistance to sulfate attack; however, this study is limited by the statistical analysis of standard test methods. Thus, more comprehensive study of sulfate attack resistance of RPC considering temperature effect and other types of sulfate solution may be needed to assess the resistance of RPC to sulfate attack incorporated with statistical analysis.

\section{Acknowledgements}

This research was supported by the Nazarbayev University Research Fund under Grant (\#SOE2017001) "Development of a Renewable Energy Storage System Using Reinforced Concrete Foundations". The authors are grateful for this supports. The authors would like to thank Nurdaulet Kutymbek, Kirill Kryzhanovskiy and Islam Mukhammedrakhym, laboratory assistant and undergraduate students of Nazarbayev University for their assistance in the laboratory work.

\section{ORCID}

Umut Bektimirova: https://orcid.org/0000-0002-8910-6631

Eldar Sharafutdinov: https://orcid.org/0000-0002-8320-3780

Chang S. Shon: https://orcid.org/0000-0003-4849-3206

Dichuan Zhang: https://orcid.org/0000-0002-9253-4178 
Jong R. Kim: https://orcid.org/0000-0002-8796-3832

\section{References}

Ahmad, S., Zubair, A., and Maslehuddin, M. (2015). Effect of key mixture parameters on flow and mechanical properties of reactive powder concrete. Construction and Building Materials, 99, 73-81.

American Society for Testing and Materials. (2016). Standard Test Method for Compressive Strength of Hydraulic Cement Mortars, ASTM C109, ASTM International, West Conshohocken, PA, USA.

American Society for Testing and Materials. (2015). Standard Practice for Use of Apparatus for the Determination of Length Change of Hardened Cement Paste, Mortar, and Concrete, ASTM C490, ASTM International, West Conshohocken, PA, USA.

American Society for Testing and Materials. (2015). Standard Test Method for Length Change of HydraulicCement Mortars Exposed to a Sulfate Solution, ASTM C1012, ASTM International, West Conshohocken, PA, USA.

American Society for Testing and Materials. (2016). Standard Practice for Dealing with Outlying Observations; ASTM E178; ASTM International: West Conshohocken, PA, USA.

Beglarigale, A., and Yazıc1, H. (2015). Pull-out behavior of steel fiber embedded in flowable RPC and ordinary mortar. Construction and building materials, 75, 255-265.

Bektimirova, U., Shon, C. S., Zhang, D., Sharafutdinov, E., and Kim, J. (2018). Proportioning and Characterization of Reactive Powder Concrete for an Energy Storage Pile Application. Applied Sciences, 8(12), 2507.

Bektimirova, U., Mukhammedrakhym, I., Shon, C. S., Zhang, D. C., and Kim, J. (2020). Effect of Aggregate Packing on Strength of Reactive Powder Concrete: Modeling and Experimental Evaluation. In Materials Science Forum (in press.) Trans Tech Publications.

Gu, Y., Martin, R. P., Metalssi, O. O., Fen-Chong, T., and Dangla, P. (2019). Pore size analyses of cement paste exposed to external sulfate attack and delayed ettringite formation. Cement and Concrete Research.

Haufe, J., and Vollpracht,
Research, 116,81-88.

Ikumi, T., Cavalaro, S. H Concrete Composites,

, T., Chen, B. C., Zhuan , gradation on strength Trans Tech Publications
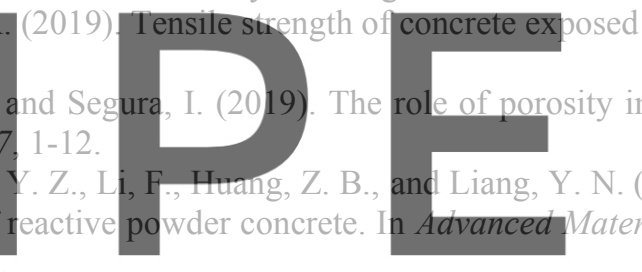

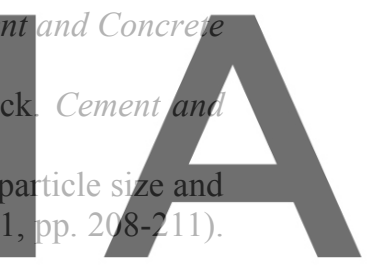

Lin, J. L., Wang, K. S., Yan, B. H., and Tarng, Y. S. (2000). An investigation into improving worn electrode

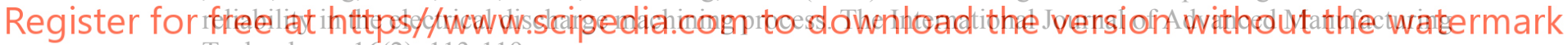
Technology, 16(2), 113-119.

Marchand, J., Odler, I., and Skalny, J. P. (2003). Sulfate attack on concrete. CRC Press.

Tixier, R., \& Mobasher, B. (2003). Modeling of damage in cement-based materials subjected to external sulfate attack. I: formulation. Journal of materials in civil engineering, 15(4), 305-313.

Tulebekova, S., Saliyev, D., Zhang, D., Kim, J. R., Karabay, A., Turlybek, A., and Kazybayeva, L. (2017, November). Preliminary analytical study on the feasibility of using reinforced concrete pile foundations for renewable energy storage by compressed air energy storage technology. In Materials Science and Engineering Conference Series (Vol. 271, No. 1, p. 012023).

Tulebekova, S., Zhang, D., Lee, D., Kim, J. R., Barissov, T., and Tsoy, V. (2019). Nonlinear responses of energy storage pile foundations with fiber reinforced concrete. Structural Engineering and Mechanics, 71(4), 363-375.

Rahimi, S., Nikbin, I. M., Allahyari, H., and Habibi, S. (2016). Sustainable approach for recycling waste tire rubber and polyethylene terephthalate (PET) to produce green concrete with resistance against sulfuric acid attack. Journal of Cleaner Production, 126, 166-177.

Sun, H., Li, Z., Memon, S., Zhang, Q., Wang, Y., Liu, B., and Xing, F. (2015). Influence of ultrafine 2CaO· SiO2 powder on hydration properties of reactive powder concrete. Materials, 8(9), 6195-6207.

Zhang, D., Kim, J., Tulebekova, S., Saliyev, D., and Lee, D. (2018). Structural Responses of Reinforced Concrete Pile Foundations Subjected to Pressures from Compressed Air for Renewable Energy Storage. International Journal of Concrete Structures and Materials, 12(1), 74. 